\title{
The Formation of Nanodispersed Composite Metal Structure with Electroslag Surfacing
}

\author{
Gennady Nikolaevich Sokolov ${ }^{1}$, Ilya Vasilevich Zorin ${ }^{1}$, Alexander Alekseevich Artem'ev ${ }^{1}$, Yuriy Nikolaevich \\ Dubtsov $^{1} \&$ Vladimir Ilyich Lysak ${ }^{1}$ \\ ${ }^{1}$ Volgograd State Technical University, Volgograd, Russia \\ Correspondence: Gennady Nikolaevich Sokolov, Volgograd State Technical University, Volgograd, Russia. \\ E-mail: naplavka34@gmail.com
}

Received: January 22, 2015

doi:10.5539/mas.v9n9p333
Accepted: February 17, 2015 Online Published: August 30, 2015

URL: http://dx.doi.org/10.5539/mas.v9n9p333

The reported study was partially supported both by RFBR (research project No. 13-08-01282 and 14-08-00868) and Council on Grants of the President of the Russian Federation (research project No. MK-4265.2014.8).

\begin{abstract}
Deposited metal requirements for cycled thermal-force operation were formulated. The influence of metal droplets and slag emulsion circular flow on the formation of an electroslag deposited metal structure is revealed. Micromorphology, ultimate composition and high-temperature properties of refractory deposited metal based on iron, nickel and nickel aluminide $\mathrm{Ni}_{3} \mathrm{Al}$ were studied. Nano-sized particles of intermetallic compounds of various origins are shown to increase the performance characteristics of refractory coatings in a cycled thermal-force operation at temperatures of 700 to $1100{ }^{\circ} \mathrm{C}$.
\end{abstract}

Keywords: electroslag surfacing, composite structure, aluminide $\mathrm{Ni}_{3} \mathrm{Al}$, hot hardness, nano-sized particles

\section{Introduction}

In order to harden pressing dies and other tools for cycled thermal-force operation at temperatures up to $1100{ }^{\circ} \mathrm{C}$ without shock loads it is efficient to use composite structure surfacing alloys (Reed, 2008; Sims, Stoloff, \& Hagel, 1995). These high-strength materials can have both an artificial and a natural composite structure. We know (Dilthey, Woeste, \& Aretov, 2006; Kivineva, Olson, \& Matlock, 1995) that wear-resistant alloys of an artificial composite structure are produced by adding carbide, nitride and boride particles and other refractory chemical compounds into the welding pool. A natural composite structure is formed under the influence of high gradient directed solidification (Petrushin, Chabina, \& Nazarkin, 2012; Povarova, et al., 2008; Povarova, et al., 2011). In this case the dendrites in the metal in the direction of solidification front the function as the alloy matrix. The eutectic solid phases at the dendrites' boundaries provide better deformation resistance to the metal. This more efficient cycled thermal-force operation type of deposited composite metal can be produced by electroslag surfacing methods (Hradecky, 1976; Kuskov, Skorohodov, \& Ryabtsev, 2001).

The object of the article is to determine the principles and develop a method of electro-slag surfacing for the formation of a creep- and wear-resistant alloy based on iron, nickel and nickel aluminide with nanodispersed composite structur.

\section{Materials and Methods}

The research was performed with powder wires and electroslag surfacing technology using a current solidification mould with a hollow electrode, electrically neutral surfacing materials being supplied into the slag through a hole in the hollow electrode (Figure 1).

Both the powder wires and the surfacing technology were developed by the authors. Experimental samples were applied to the surface of steel X20 using ANF-6 flux; the surface of the slag pool was protected with argon. Three types of deposited metal were studied based on: iron X $200 \mathrm{CrMoNi} 28-7-2$, nickel X $250 \mathrm{CrNiMoNb}$ 22-66-4-2 and nickel aluminide $\mathrm{Ni}_{3} \mathrm{Al}$ (X 50 CrNiAlMoZr 22-65-6-3-3). 


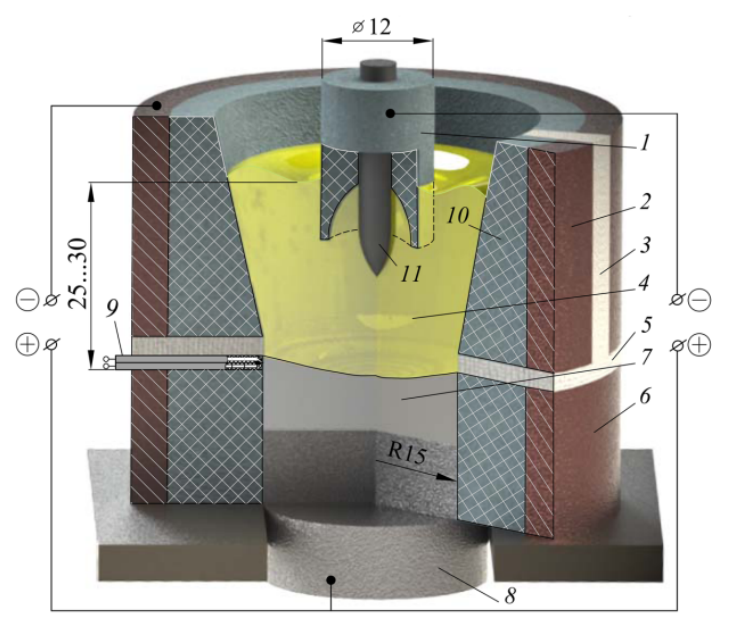

Figure 1. Electroslag surfacing diagram in a current supplying a solidification mould: 1 - hollow graphite electrode; 2 - current supply section; 3 - insulator in a process cut; 4 - slag pool; 5 - electrically-insulating layer; 6 - forming section; 7 - molten metal bath; 8 - product; 9 - thermocouple; 10 - graphite refractory; 11 composite wire

The structure, micromorphology and element composition of the deposited metal were studied with optical, electron and atomic-powered microscopy. The composition and distribution of alloy elements in the structural components were determined with energy-dispersive analysis in the secondary electron signal mode. Deposited metal deformation resistance was estimated by its hardness at high temperature. Deposited metal high-temperature scratch-hardness tests were performed in an inert atmosphere with a diamond cone, with a cone vertex angle of $120^{\circ}$ and a curve radius of $200 \mu \mathrm{m}$ at a load of 0.5-1.0 N. Wear resistance criteria was the indicator $\mathrm{I}=1 / \lg V_{d}$, where $V_{d}$ is the deformed metal volume at a constant temperature at the track segment of $10 \mathrm{~mm}$ long remaining after the indenter movement.

\section{Theoretical Justification of the Deposited Metal and the Process of Its Development}

\subsection{Deposited Metal Requirements}

Computations and experiments (Schumon, 1968) show that thermo-force significantly increases the diffusion rate of alloy elements in the thin surface layer of deposited metal. This leads to metal homogenization and reduces its wear resistance. For example, Figure 2 shows that in the initial period of pressing in the die operation, when stresses are at a maximum, the diffusion rate of chromium and molybdenum increases by several orders.

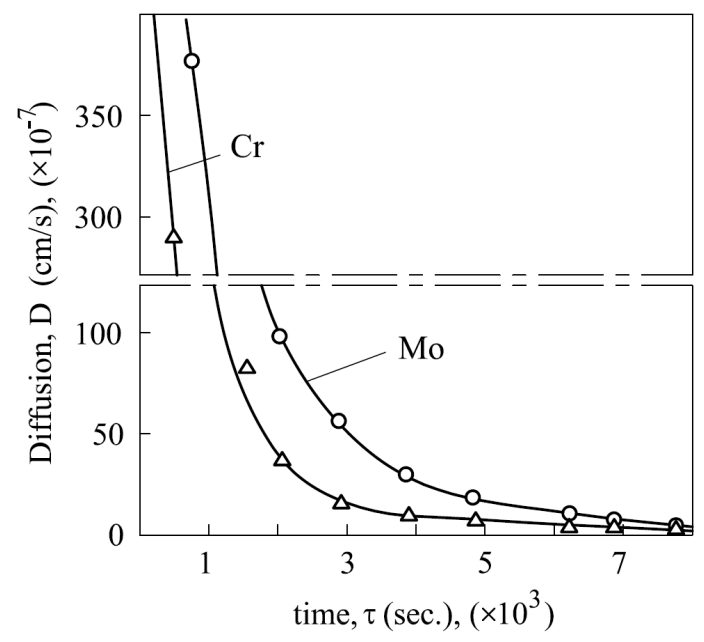

Figure 2. Influence of the contact time t of the die surface with surfacing by X $200 \mathrm{CrMoNi}$ 28-7-2 alloy and steel forgings heated to $700{ }^{\circ} \mathrm{C}$ on the diffusion rate $D$ of chromium and molibdenum in the contact layer of metal $(100 \ldots 150 \mu \mathrm{m})$ 
Hence, in order to increase the lifetime of deforming hot metal tools it is better to use surfacing alloys that resist homogenization. Equation (1) (Schumon, 1968) shows that the metal homogenization time $t$ can be increased in two ways:

$$
D \approx \frac{l^{2} \ln \left(C-C_{0}\right)}{\pi^{2} t},
$$

where $D$ is the diffusion coefficient of alloying elements; $l$ is the distance between hardening phases; $t$ is the total time of the deposited metal and the hot alloy contact (the alloy-homogenization time); $C-C_{0}$ is the alloying elements concentration gradient.

The first method creates a certain degree of structural and chemical inhomogeneity in the metal characterized with the coefficient $n_{c}$

$$
n_{c}=l^{2} \ln \left(\frac{C-C_{0}}{\pi^{2}}\right)
$$

The second method reduces atom diffusion mobility in the alloy matrix and in the hardening phases. Thus, the formation of a surfacing alloy composite structure for cycled thermal-force operation shall be considered as diffusional, structural and technological characteristics based on the following principles:

- $\quad$ in deposited metal, identification is required of the best atomic per cent ratio of carbide-forming elements and carbon responsible for the formation of a strong framework of carbide eutectics and for dilution resistance at high temperatures of mono- and complex carbides;

- within an operation temperature range in the deposited metal matrix, reduction is required in the atom diffusion mobility of the basic and alloying element depending upon the matrix crystal lattice as well as the number, morphology, distribution and type of sub-dispersed hardening phases;

- $\quad$ in order to provide deposited metal resistance to hot cracking and thermal fatigue cracking, it is necessary to establish the best ratio of matrix alloy and disintegrated carbide eutectic in the metal that does not form closed-link chains around primary dendrites;

- the surfacing process shall provide a minimal bending deflection of slag (gas) -metal interface to form a flat solidification front in a welding pool to produce directional positioning of primary dendrite.

In this respect, within the range of maximum temperatures of $650-700{ }^{\circ} \mathrm{C}$, it is efficient to use comparatively inexpensive carbonic chromium and molybdenum alloys of the $\mathrm{Fe}-\mathrm{Cr}-\mathrm{Mo}-\mathrm{C}$ system as surfacing alloys, while at temperatures up to $750-950{ }^{\circ} \mathrm{C}$ the nickel-based deposited metal of the Ni-Cr-Mo-C system is effective for cycled thermal-force operation (Whelan, 1979; Wu, \& Redman, 1994). For surfacing tools operating at temperatures of $950-1100{ }^{\circ} \mathrm{C}$ it is efficient to use refractory alloys with matrices based on nickel aluminide $\mathrm{Ni}_{3} \mathrm{Al}$ (Lippold, Kiser, \& DuPont, 2009; Liu, 1993; Povarova, K. B., et al., 2008; Stoloff, 1989); these alloys are used in the aerospace industry as a construction material for gas turbine vanes. Powder wires and composite wires (Kivineva, Olson, \& Matlock, 1995) have been developed to produce such alloys in deposited metal.

\subsection{Electroslag Surfacing Process Study}

We know (Dilawary, 1978; Liu, Zang, Jiang, Geng, \& Yao, 2012; Palti, \& Shevtsov, 2002) that in the process of electroslag welding and surfacing, due to technological factors, the welding pool melt front of solidification has the deflected shape which influences the deposited metal quality. The flat solidification front providing dendrite directional positioning can be produced by surfacing with a current supplying a solidification mould and a two-circuit DC power supply (Figure 1) (Sokolov, Ryabchuk, \& Lysak, 2008).

It is experimentally proved that this surfacing technology enables the energy environment in the slag pool to change significantly. The slag areas with the highest potential are close to the hollow electrode in the bottom of the current supply section which results in a high concentration of current lines (Figure 3). This contributes to high-temperature generation in the spherical hollow space of the graphite electrode with its maximum up to 3500 ${ }^{\circ} \mathrm{C}$. However the maximum volume electromagnetic force does not change abnormally the shape of the slag-metal interface.

A mathematical model dealing with slag gravity flow caused by a significant (up to $1500{ }^{\circ} \mathrm{C}$ ) temperature drop between the overheated near-electrode area of the slag pool and the slag body adjacent to the slag-metal 
interface can explain the physics of the above phenomenon. The heat convection influence induced by the temperature drop on hydrodynamic processes in the slag pool was previously neglected. This is due to the temperature drop in a conventional electroslag process not usually exceeding $300-400{ }^{\circ} \mathrm{C}$, and the Archimedes forces density in the area of the main current is one order less than the electromagnetic force density (Palti, \& Shevtsov, 2002).

An electroslag process model demonstrated slag circulation flow with metal (emulsion) droplets in a solidification mould (Sokolov, Ryabchuk, \& Lysak, 2008). Liquid slag was believed to be the dispersion phase while molten metal droplets were considered to be the dispersed phase. Two important parameters were considered: temperature drop and the emulsion 'thinning' effect, the rheological state of the emulsion being described by Oswald de Ville's law (Bernadskaya, Valentinova, Mishta \& Ryabchuk, 2005). In the vertical plane (Figure 4), circulation is conditioned by two factors - the temperature difference between the areas near the upper and lower electrodes (central circulation flow) and the temperature difference between the areas near the side and bottom electrodes (near wall flow), in addition to the electric and magnetic field density. In the horizontal plane, the rotational flow is conditioned by electric and magnetic fields only. Since metal pool surface formation quality is mainly influenced by emulsion flow in the vertical plane, we will consider only these movements.

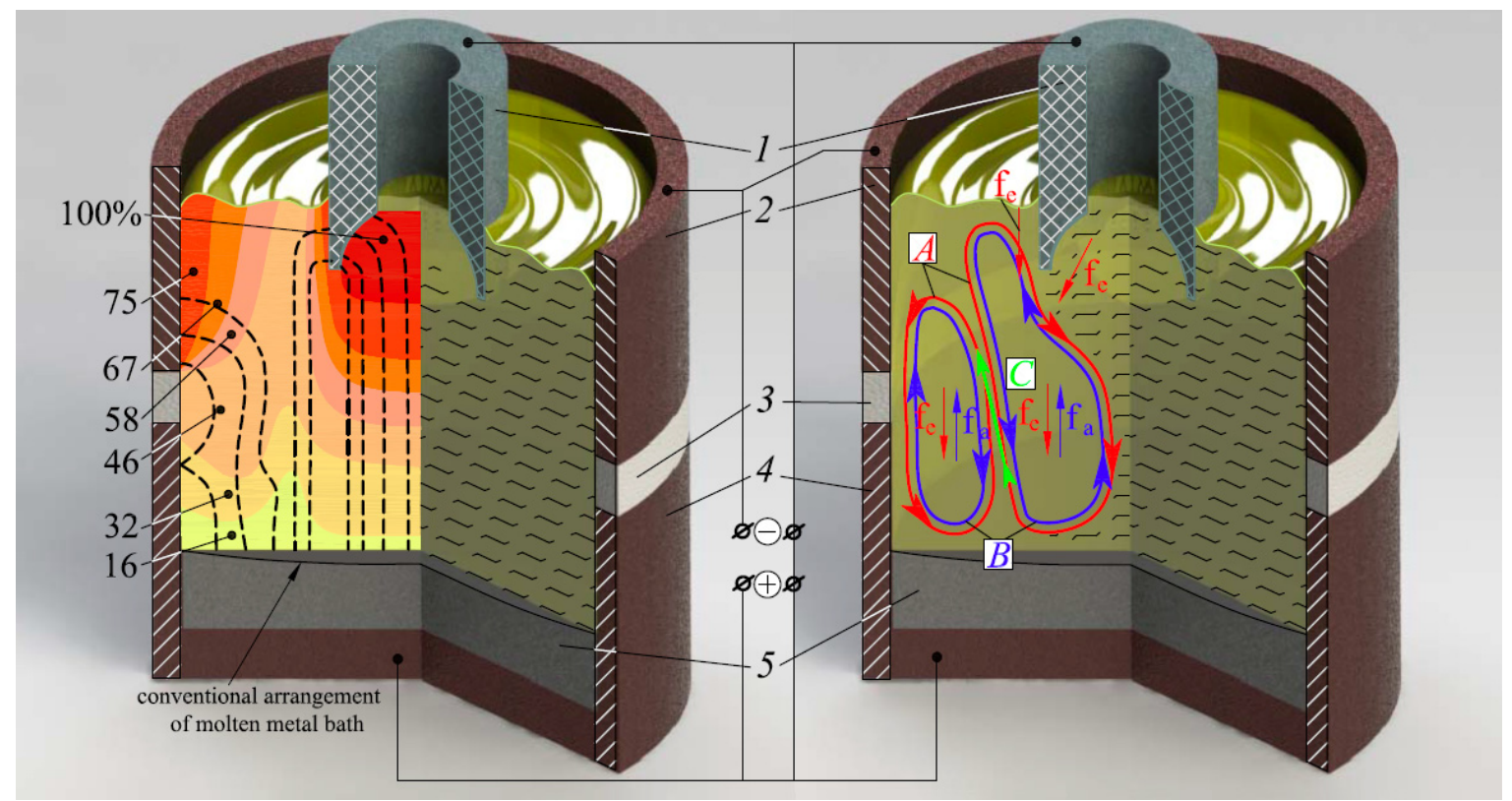

(a)

(b)

Figure 3. Distribution of the potential field (a) and current field (b) for the direct current two-circuit power supply of a slag pool: 1 is a hollow electrode; 2 is a current supply section; 3 is an insulator; 4 is a forming section; 5 is a product; —_ are voltage equipotential lines; --- are current lines. Electrolyte flows initiated by power supply section electric field and hollow electrode (A), heat convection flows (B), hydraulic pressure head direction $(\mathrm{C})$

In order to determine the velocity of the emulsion circulation flow caused by heat convection, let us consider the following problem. Suppose a cylinder rod with diameter $d$ is located along the axis of a cylindrical vessel with diameter $D$, filled with emulsion, with $d$ being much smaller than $D$, and the rod surface temperature $t_{\text {rod }}=$ const higher than the cylinder wall temperature (Figure 4). The emulsion far from the cylindrical rod is motionless (no gravitational flow), its temperature far from the cylindrical rod is constant and equals $t_{0}$. Under the statement of the problem, $t_{\text {rod }}$ is greater than $t_{0}$. The emulsion volume is so large that free gravitational flow emerging near the other bodies in the same volume does not influence the flow near the cylindrical rod, this flow being conditioned by heat convection and electromagnetic force. 


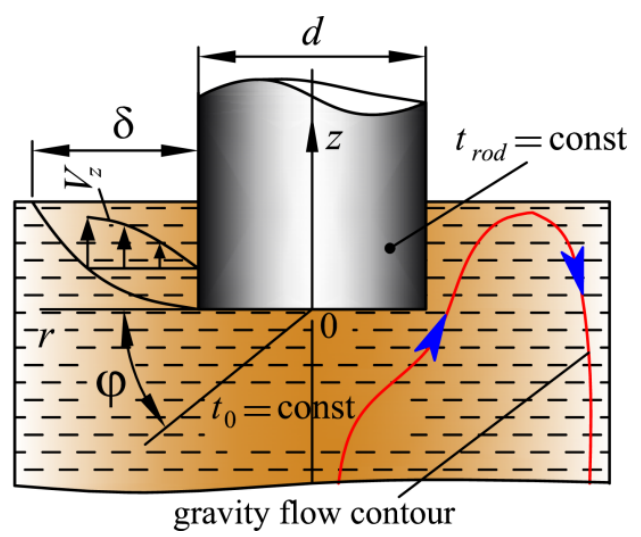

Figure 4. Diagram for determining flow velocity of slag emulsion and metal droplets in a cylindrical coordinate system (ref. to the text)

In order to simplify the solution of the problem, let us assume the following: inertia forces are negligible compared to the gravity and viscous friction force; the pressure gradient is zero; liquid thermophysical parameters (except density) are constant; density is a linear function of temperature.

We will consider the physics of the most intensive slag gravitation flow near the cylindrical rod in the cylindrical coordinate system. With regard to the above assumptions, the Z-component of the gravitational flow equation can be represented as follows:

$$
k \frac{\partial}{\partial r}\left\{\frac{\partial V_{z}}{\partial r}\left[\left(\frac{\partial V_{z}}{\partial r}\right)^{2}+\left(\frac{\partial V_{\varphi}}{\partial r}\right)^{2}\right]^{\frac{n-1}{2}}\right\}=-g\left(\rho-\rho_{0}\right)
$$

where $g$ is gravity acceleration, $\mathrm{m} / \mathrm{s}^{2}, \rho_{0}$ is slag density far from the cylindrical $\mathrm{rod}, \mathrm{kg} / \mathrm{m}^{3}, \rho$ is slag variable density in the gravity flow area, $\mathrm{kg} / \mathrm{m}^{3}, V_{z}, V_{\varphi}$ are respectively vertical and tangential components of velocity, $\mathrm{m} / \mathrm{s}$.

Solving this equation considering the temperature change in the emulsion moving layer and the emulsion density linear dependency of temperature, we obtain the following gravity flow equation:

$$
k \frac{\partial}{\partial r}\left\{\left(\frac{\partial V_{z}}{\partial r}\right)^{n}\left[1+\frac{\left(\frac{\partial V_{\varphi}}{\partial r}\right)^{2}}{\left(\frac{\partial V_{z}}{\partial r}\right)^{2}}\right]^{\frac{n-1}{2}}\right\}=-\rho_{0} g \beta t_{r o d}^{*}\left(1-\frac{r}{\delta}\right)^{2}
$$

Solving this equation we obtain gravity flow velocity in the following form:

$$
\bar{V}_{z}=\left(\frac{n}{2 n+3}\right)\left(\frac{\rho_{0} g \beta t_{r o d}^{*}}{3 k^{*}}\right)^{\frac{1}{n}} \delta^{\frac{n+1}{n}}
$$

where $k^{*}$ is the reduced characteristic of consistence.

In order to determine the unknown value $\delta$ (Figure 3 ) we will use the integral equation of continuity and the heat balance equation. Solving them and integrating the result we find: 


$$
\delta=\left[\frac{(2 n+3)(3 n+1) \cdot G \cdot 3^{\frac{1}{n}}}{n(2 n+1)} \cdot \frac{k^{\frac{1}{n}} \lambda z}{c_{p} \rho^{\frac{n+1}{n}}\left(g \beta t_{\text {rod }}^{*}\right)^{\frac{1}{n}}}\right]^{\frac{n}{3 n+1}}
$$

The above dependencies were used to calculate the velocity of metal droplets and slag emulsion circular flow caused by heat convection. Input data for the calculation were thermophysical constants and indicators for slag ANF-6 $\left(70 \% \mathrm{CaF}_{2}\right.$ and $\left.30 \% \mathrm{Al}_{2} \mathrm{O}_{3}\right)$, and metallic melt of nickel aluminide $\mathrm{Ni}_{3} \mathrm{Al}$ at temperatures typical of the analysed electroslag surfacing process. The value of molten slag movement velocity calculated with no regard to the temperature drop influence is $0.042 \mathrm{~m} / \mathrm{s}$ (Sokolov, Ryabchuk, \& Lysak, 2008). In our calculations, the average velocity of slag circulation is $0.046 \mathrm{~m} / \mathrm{s}$. Since these are counter-current flows, the resultant velocity in the slag pool is ten times less.

The analysis of the movement model for slag with metal droplets proved that a moderate resultant force is formed in two toroidal slag flows rotating round the electrode axis; this force influences the emulsion movement and enables the life of metal droplets to be increased, increasing their metallurgical processing efficiency. Due to the pressure quadratic dependence of liquid flow velocity, the emulsion flow pressure on the molten metal surface decreases almost one hundred-fold. This results in the formation of a flat slag-metal interface without catering for the typical conventional electroslag welding and surfacing which influences the deposited metal quality.

\section{Results and Discussion}

The survey of X 200 CrMoNi 28-7-2 metal surfaced with the new electroslag process showed that the composite structure of elecroslag surfaced metal with an iron based matrix consists of a molybdenum saturated solid solution (a microhardness of 3800-3900 MPa). The metal contains sub-dispersed x-phase particles, with the $\mathrm{x}$-phase kinetics being similar to the $\sigma$-phase and composed of $\mathrm{Fe}_{12} \mathrm{Cr}_{36} \mathrm{Mo}_{10}$. There are also carbides $\mathrm{Mo}, \mathrm{Cr}$, $\mathrm{Fe})_{7} \mathrm{C}_{3}$ (a micro-hardness of 8000-10000 MPa) and 20-30 volume per cent of carbide eutectic composed of carbides (Mo, $\mathrm{C}, \mathrm{Fe})_{23} \mathrm{C}_{6}$ and $\mathrm{MoC}$ with a micro-hardness of 7300-7500 MPa (Figure 5).

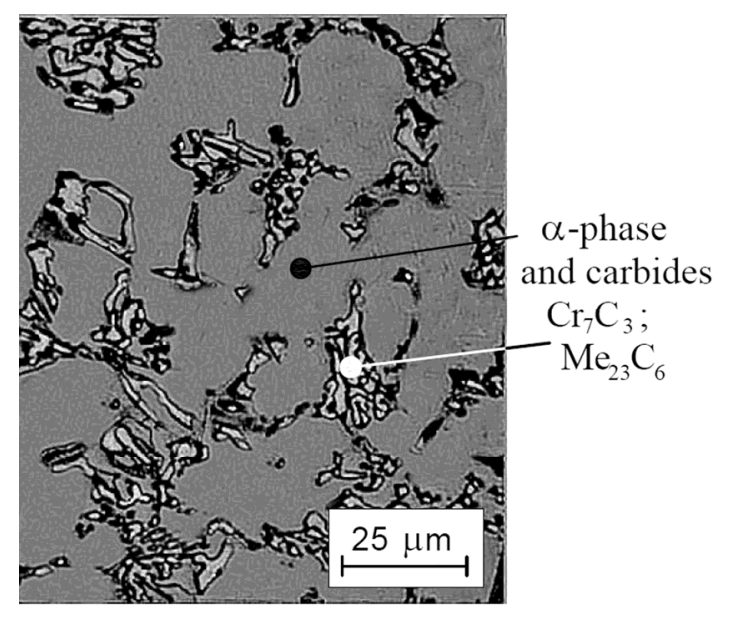

a) overall view of the structure $(\times 400)$

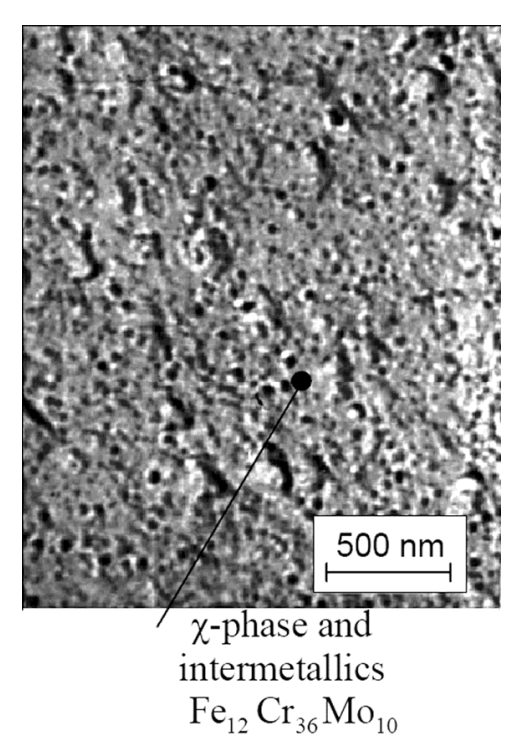

b) solid solution with intermetallic compounds FeCrMo $(\times 20 \mathrm{~K})$

Figure 5. Deposited metal structure X 200 CrMoNi 28-7-2

It was established (Figure 6, a) that, as a result of deposited metal hardening due to the formation of a strong carbide framework, and due to the formation of nano-sized $(80-100 \mu \mathrm{m})$ iron, chromium and molybdenum 
intermetallic compounds in a plastic hard solution, the deposited metal hardness at $700{ }^{\circ} \mathrm{C}$ after $5-6$ hours of testing does not noticeably reduce.

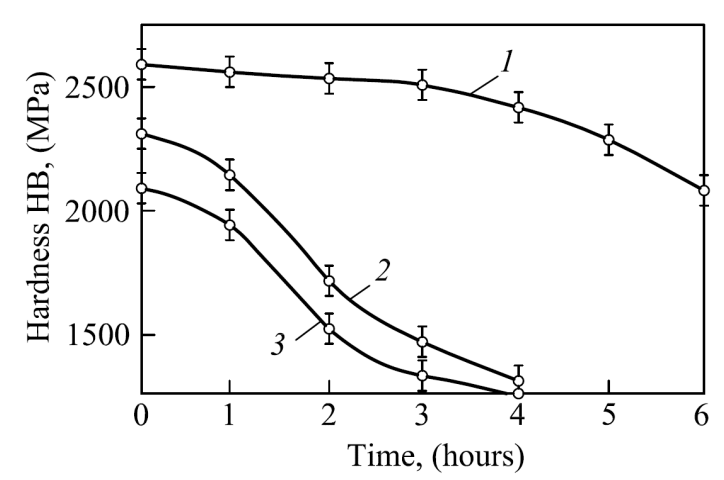

(a)

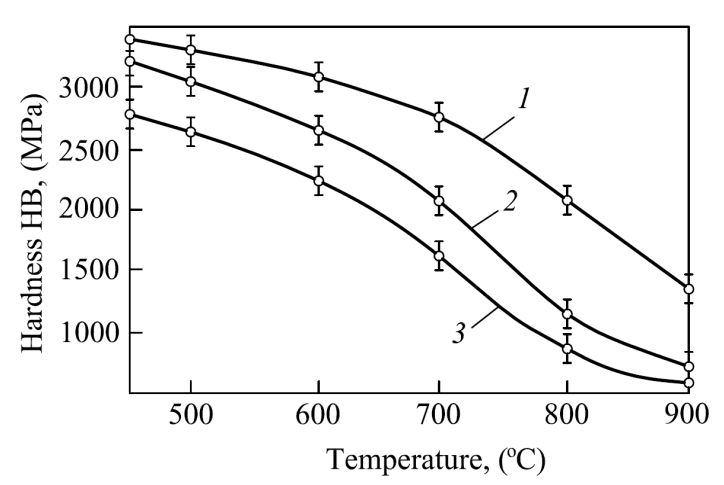

(b)

Figure 6. Dependence of hot Brinell hardness of deposited metal X $200 \mathrm{CrMoNi} 28-7-2$ of hold time at a temperature of $700{ }^{\circ} \mathrm{C}$ (a) and of test temperature (b): deposited metal; 2 - steel X30 CrWVSi 2-8; 3 - steel X40

CrWVMo 2-5

In comparison, the hardness of chromium and tungsten heat-resistant tool steel, used for hot deformation die production, decreases fast after 1.5-2 hours of work. The 'hot' hardness studies at wide temperature ranges (Figure 6, b) showed that the experimental alloy of the Fe-Cr-Mo-C system significantly exceeds the existing tool steels in this parameter.

The research studied the structure of nickel-based deposited metal with uniformly distributed carbide eutectic with a micro-hardness of $4000 \mathrm{MPa}$; nickel and carbides based alloyed solid solutions $\mathrm{NbC}, \mathrm{Mo}_{2} \mathrm{C}$ (Figure 7).
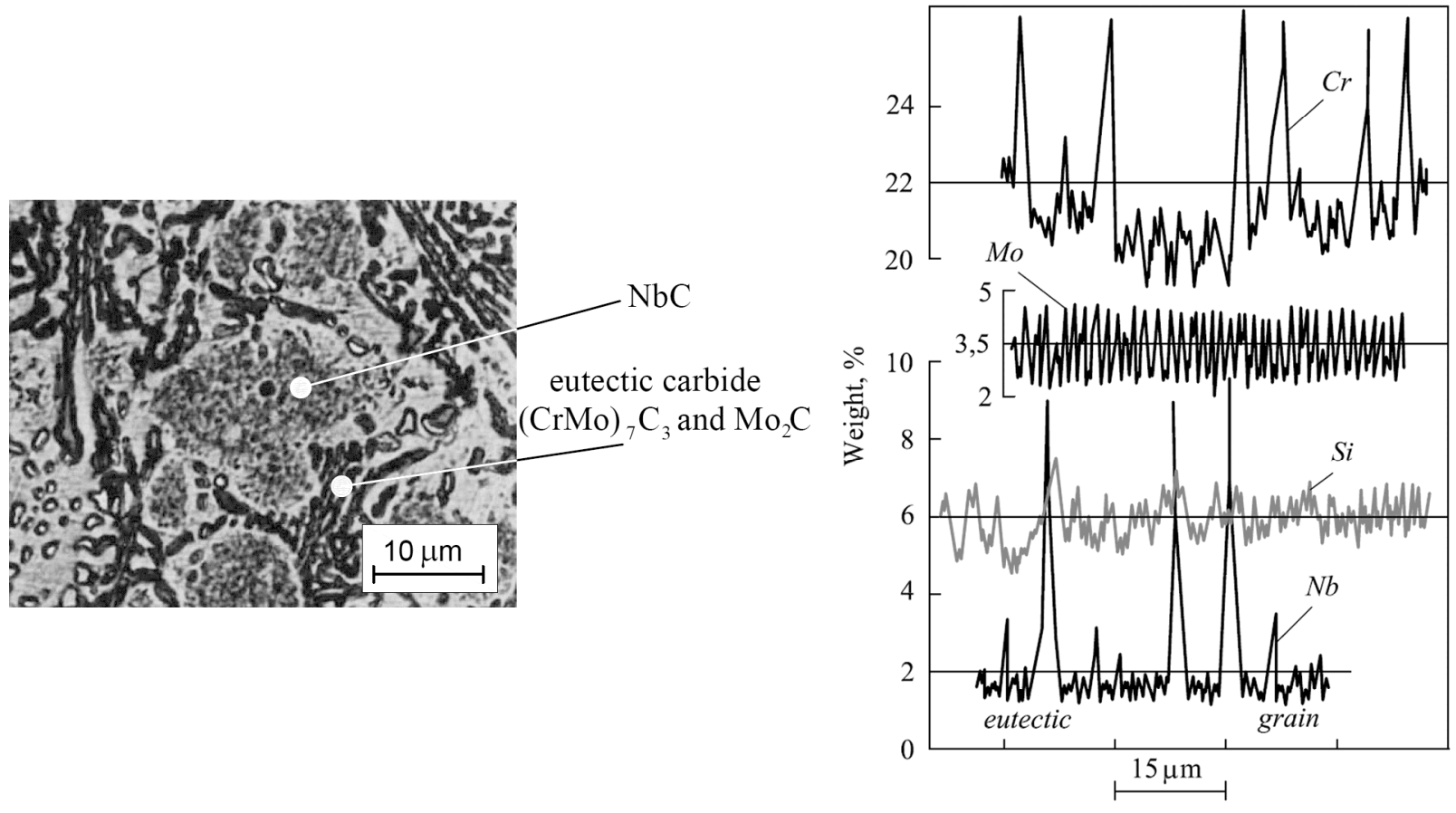

(a)

(b)

Figure 7. Microstructure of deposited metal $(\times 600)$ X $250 \mathrm{CrNiMoNb} 22-66-4-2$ (a) and alloying element distribution (b). Columbium content 1.82 (\% mass) 
Columbium sub-dispersed carbides, separating mainly on chromium and nickel $\gamma$-solid solution crystal lattice defects, make the solution harder. They also influence relatively uniform distribution of silicon and carbide eutectic (Figure 7, b). Molybdenum is also evenly distributed in the deposited metal, confirming its active chemical bonding with nickel, and is one of the reasons for the increased heat resistance of such alloys compared with nickel alloys containing tungsten instead of molybdenum.

Comparative 'hot' hardness test data for the deposited metal of various structural classes (Figure 8) indicate that the considered material is highly resistant to cycled thermal-forces at temperatures up to $900{ }^{\circ} \mathrm{C}$.

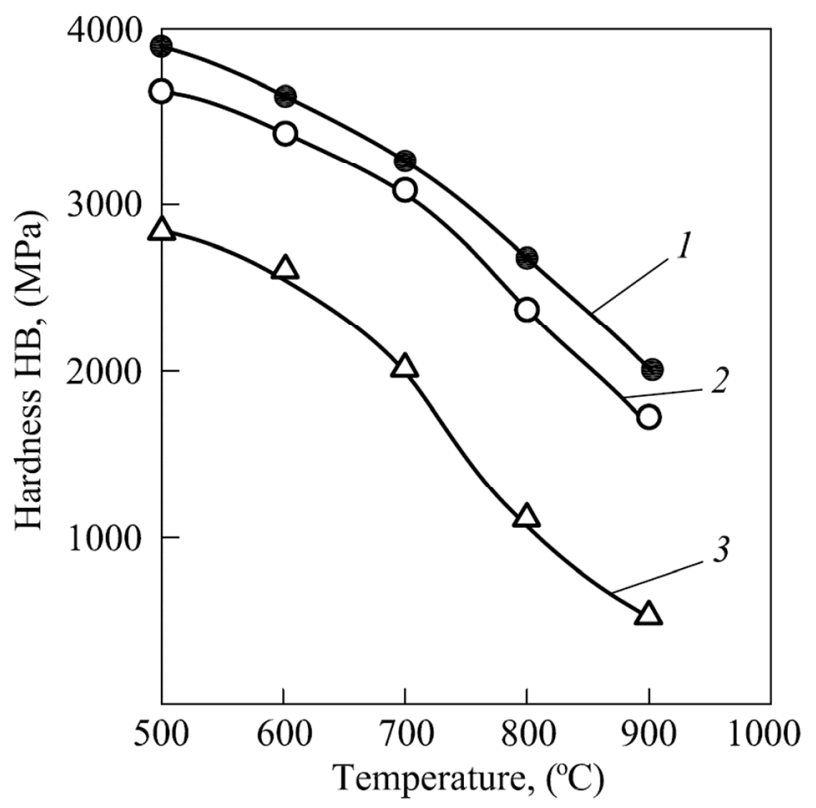

Figure 8. The influence of test temperature $\mathrm{T}$ on high-temperature Brinell hardness of deposited metal: 1 - Hastelloy C; 2 - X 250 CrNiMoNb 22-66-4-2; 3 - X30 CrWSiV 3-9

Metallographic research of nickel-aluminide based deposited metal showed that the metal has a complex heterophased structure. Its structure (Figure 9) consists mainly of $\gamma^{\prime}-\mathrm{Ni}_{3} \mathrm{Al}$ alloyed aluminide dendrites with a micro-hardness of 2800-3200 MPa (Figure 9, a). The dendrites contain disordered $\gamma$-hard nickel-based solution, alloyed with chromium, tungsten, molibdenum, tantalum, titanium and iron; dispersed secondary $\gamma_{\text {secondary }}$-phases; intermetallic compounds CrNiMoTiZr ( $\kappa$-phase) (Figure 9, b); and refractory carbides $\mathrm{Ta}_{2} \mathrm{C}, \mathrm{WC}, \mathrm{Mo}_{2} \mathrm{C}$. Interdendritic spaces contain irregularly shaped aluminides $\gamma_{\text {eutectic }}^{\prime}$ of eutectic origin with $\kappa$-phase precipitations (a microhardness of 4600-4800 MPa).

Carbide eutectic made up of $\mathrm{Cr}_{7} \mathrm{C}_{3}$ and $\mathrm{Mo}_{2} \mathrm{C}$ carbides as well as $\gamma_{\text {secondary }}^{\prime}$ phase (microhardness 5500-5700 MPa) are uniformly distributed among primary crystallites $\gamma^{\prime}$. The total content of $\gamma^{\prime}-\mathrm{Ni}_{3} \mathrm{Al}$ phases of various origin in the deposited metal is $85-90$ vol. \%.

The surface electronic probing of deposited metal proved that alloy composition is characterized by significant chemical micro-inhomogenity which affects the nickel aluminium ratio, thus influencing the formation of aluminide $\gamma^{\prime}$ (Figure 9, c-d). This correlation is very close to the stoichiometric in primary dendrite crystallite areas located in nickel oversaturated axial volumes and in the spaces among them.

The scanning of a metallographic sample surface in a dendrite $\gamma^{\prime}$ cross-section area has revealed nano-sized particles $\gamma_{\text {secondary }}^{\prime}$ distributed uniformly in solid solution based on $\gamma^{\prime}+\gamma$; these particles condition metal structure dispersion (Figure 10).

It stands to reason that the increased heat resistance of deposited metal in question can be explained by a concerted action of two types of structural hardening. The first type of hardening is determined by the stable composite structure preserved for an extended period of time, composed of a strong framework of $\gamma_{\text {secondary }}^{\prime}$-phase and carbide eutectic with a plastic matrix in the dendrite-shaped solid solution form alloyed with refractory elements; the solution itself is made of eutectic based on $\gamma^{\prime}+\gamma$. The second type of structural hardening is characterized by the considerable volumetric portion in the alloy of thermodynamically stable nano-sized particles of $\gamma_{\text {secondary }}^{\prime}$-phase and $\kappa$-phase micro-particles of stable size, morphology and distribution. 


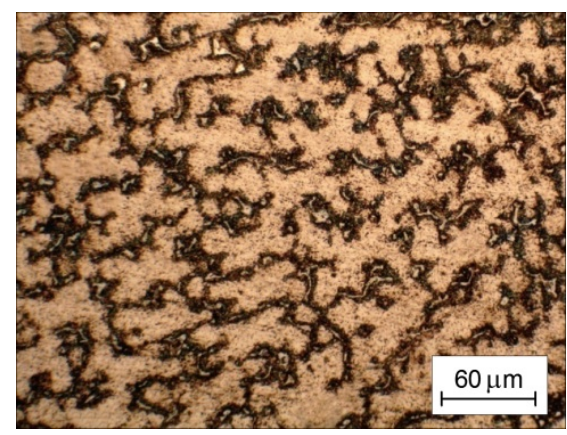

(a)

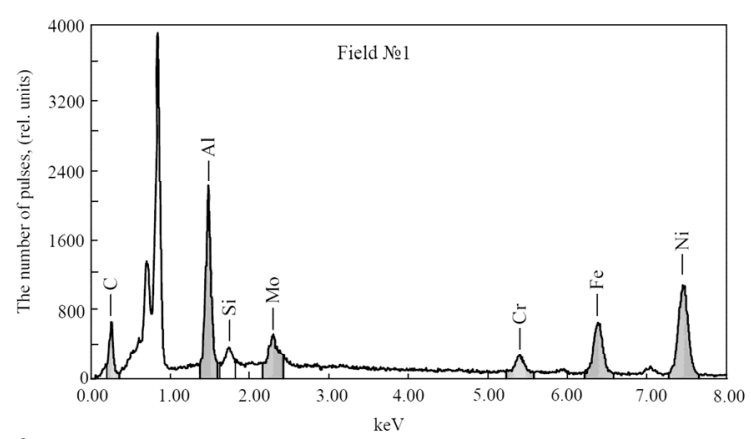

(c)

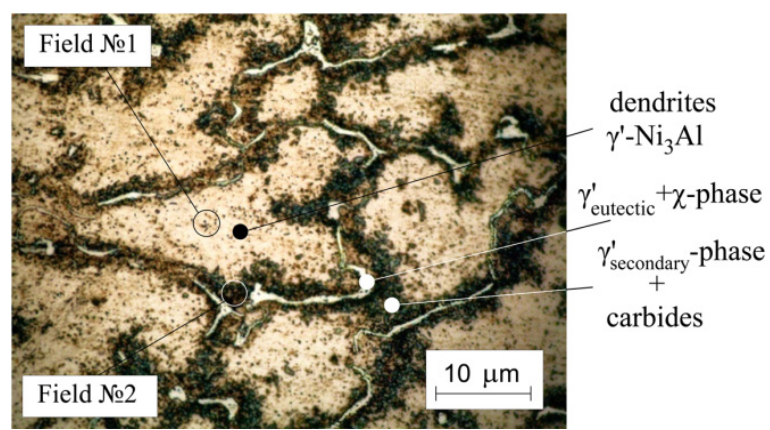

(b)

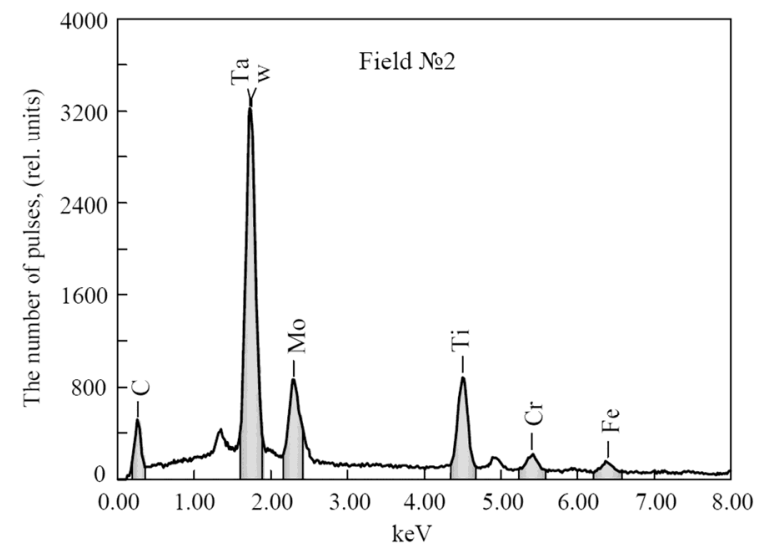

(d)

Figure 9. The structures of surfaced metal based on aluminide nickel: overall view $\times 200$ (a), $\times 1000$ (b) and typical areas of surface electronic probing $(c, d)$

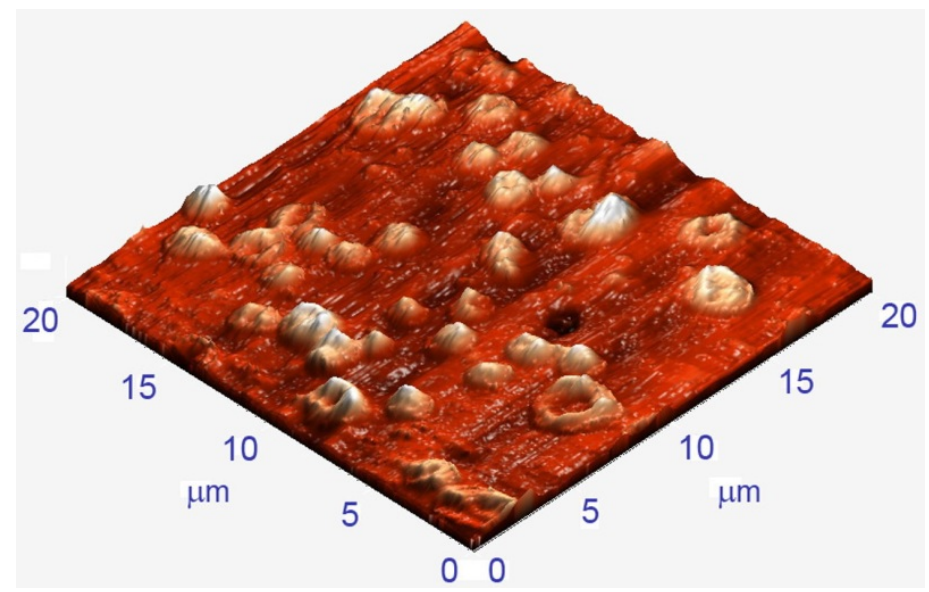

Figure 10.3D image of surfaced metal surface in dendrite $\gamma^{\prime}-\mathrm{Ni}_{3} \mathrm{Al}$ cross-section

The test results of the comparative analysis for various structural classes of the surfaced metal (Figure 11 and Figure 12) indicate that the produced electroslag surfaced alloy based on $\gamma^{\prime}-\mathrm{Ni}_{3} \mathrm{Al}$ has an increased wear resistance at temperatures of $950-1100{ }^{\circ} \mathrm{C}$. 


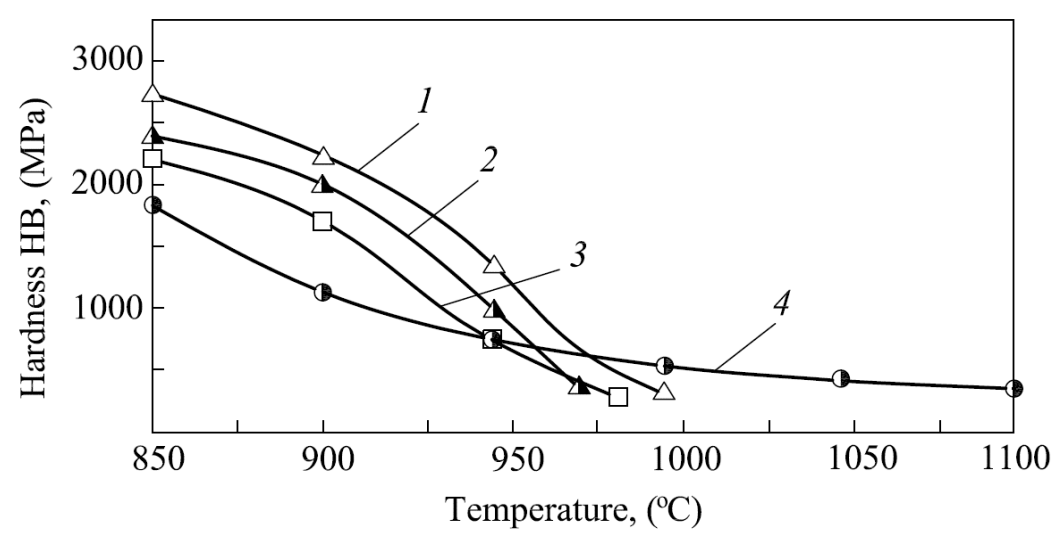

Figure 11. Change of deposited metal hardness $H B$ at high temperatures $T: 1-$ stellite X160CrCoWNi 28-60-8; 2 - Hastelloy-C; 3 - X 250 CrNiMoNb 22-66-4-2; 4 - deposited metal with matrix based on $\gamma^{\prime}-\mathrm{Ni}_{3} \mathrm{Al}$

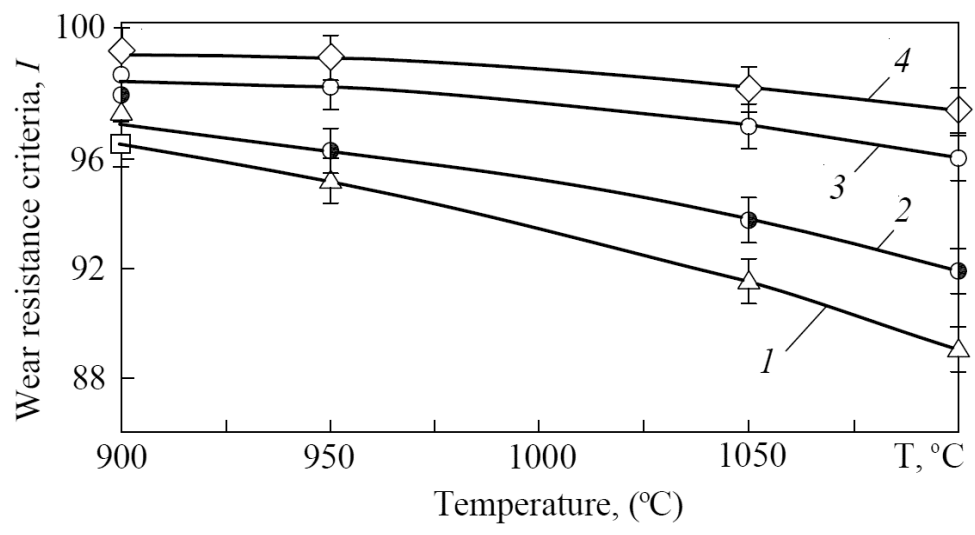

Figure 12. Dependence of wear resistance indicator $I$ during metal scleroscope tests of test temperature $T: 1-\mathrm{X}$ 30 CrWSiV 3-9; 2 - X 260 CrMoNiNb 28-6-2; 3 - X 240 CrNiMoNb 25-65-4-2; 4 - deposited metal with matrix based on $\gamma^{\prime}-\mathrm{Ni}_{3} \mathrm{Al}$

Full-scale industrial tests proved that the developed heat-resistant alloys deposited on various metallurgical tools and dies operating at $700-1100{ }^{\circ} \mathrm{C}$ increased their wear resistance by $2-2.5$ times compared to forged tools made of chromium-tungsten-molibdenum refractory steels.

\section{Conclusions}

1. The new electroslag surfacing process using a conductive solidification mould and its two-circuit power supply enables high-temperature metal of high quality with a natural composite structure to be achieved.

2. The natural composite is a combination of carbide eutectic's strong framework and plastic matrix with evenly spread hard-melting nano-sized phases. It enables wear resistance of tools and machine parts exposed to cycled thermo-force to be increased.

3. For long-term processing at temperatures over $1000{ }^{\circ} \mathrm{C}$ it is preferable to use deposited metal based on intermetallic compound $\mathrm{Ni}_{3} \mathrm{Al}$ with a composite structure stabilized with nano-sized pro-eutectoid constituents. This neutralizes the annealing processes developing in alloys at cycled thermo-force exposure.

\section{Acknowledgments}

The reported study was partially supported both by RFBR (research project No. 13-08-01282 and 14-08-00868) and Council on Grants of the President of the Russian Federation (research project No. MK-4265.2014.8).

\section{References}

Bernadskaya, E. A., Valentinova V. V., Mishta, Pav. V., \& Ryabchuk G. V. (2005). Degassing of a nonlinearly viscous liquid flowing over the heated surface of a tapered rotor. Theoretical Foundations of Chemical Engineering, 39(2), 163-169. http://dx.doi.org/10.1007/s11236-005-0056-x 
Dilawary, A. (1978). An analysis of heat and fluid flow phenomena in electroslag welding. Welding Journal, 1, $116-122$.

Dilthey, U., Woeste K., \& Aretov I. (2006). Modification of the electroslag process opens us possibilities with regard to weld surfacing. Welding and Cutting, 4, 215-220.

Hradecky, M. (1976) The experience with VUZ-NPV-1 surfacing machine used at VTZ chomutov for electroslag surfacing of pilger rolls. IV-th Inernational Electroslag Welding and Surfacing Symposium-Proceedings. Part IV. Bratislava. September 22-24, 1-9.

Kivineva, T. I., Olson, D. L., \& Matlock D. K. (1995). Particulate - reinforced metal matrix composite as a weld deposit.Welding Journal, 4, 83-92.

Kuskov, Y. M., Skorohodov V. N., \& Ryabtsev I. A. (2001). Electroslag surfacing (p. 180). Moscow: Science and Technology.

Lippold, J. C., Kiser, S. D., \& DuPont J. N. (2009). Welding Metallurgy and Weldability of Nickel-Base Alloys (p. 440). Hoboken: Wiley and Sons.

Liu C. T. (1993). $\mathrm{Ni}_{3} \mathrm{Al}$ Aluminide Alloys. Proceedings of the First International Symposium on Structural Intermetallics, Warrendale, Pennsylvania: The Minerals, Metals and Materials Society, 365-377.

Liu, F., Zang X., Jiang Z., Geng X., \& Yao M. (2012). Comprehensive model for a slag bath in electroslag remelting process with a current-conductive mould. International Journal of Minerals Metallurgy and Materials, 19(4), 303-311. http://dx.doi.org/10.1007/s12613-012-0555-9

Palti, A. M., \& Shevtsov V. L. (2002). Effect of electromagnetic forces on flow of slag at the surface of a consumable electrode in the electroslag process. Welding International, 16(9), 17-19. http://dx.doi.org/10.1080/09507110209549606

Petrushin, N. V., Chabina, E. B., \& Nazarkin, R. M. (2012). Design of refractory intermetallic alloys on the base of $\gamma^{\prime}$-phase with high melting temperature. Part 1. Metalloved. Term. Obrab. Met., 2, 32-38. http://dx.doi.org/10.1007/s11041-012-9458-7

Povarova, K. B. et al. (2011). $\mathrm{Ni}_{3} \mathrm{Al}$-base structural refractory alloys: fabrication, structure and properties. Materialovedenie, 4, 39-48.

Povarova, K. B., et al. (2008). Very light heat resistant nanostructured alloys based on $\mathrm{Ni}_{3} \mathrm{Al}$ for aircraft engine building and power engineering industry. Voprosy Materialovedeniya, 2, 85-93.

Reed, R. C. (2008). The Superalloys: Fundamentals and Application (p. 338). Cambridge: Cambridge University Press.

Schumon, P. D. (1968). Phizicheskoye metallovedeniye: Diffusion (p. 490). Moscow: Mir.

Sims, C. T., Stoloff, N. S., \& Hagel, W. K. (1995). Superalloys II. Refractory Materials for Aerospace and Industrial Power Plants [Russian translation] (p. 384). Moscow: Metallurgiya.

Sokolov, G. N., Ryabchuk, G. V., \& Lysak, V. I. (2008). Forming a composite structure based on wear-resistant alloys in electroslag surfacing. Steel in Translation, 38(11), 906-909. http://dx.doi.org/ 10.3103/S0967091208110065

Stoloff, N. S. (1989). The Physical and mechanical metallurgy of $\mathrm{Ni}_{3} \mathrm{Al}$ and its alloys. International Material Rev., 34(1), 150-183. http://dx.doi.org/10.1179/imr.1989.34.1.153

Whelan, E. (1979). Hardness and abrasive wear resistance of Ni-Cr-Mo-C hard-facing alloys. Journal of Metals, 31(1), 15-19. http://dx.doi.org/10.1007/BF03354470

Wu, J. B. C., \& Redman, J. E. (1994). Hard-facing with Cobalt and Nickel Alloys. Welding Journal, 9, 63-68.

\section{Copyrights}

Copyright for this article is retained by the author(s), with first publication rights granted to the journal.

This is an open-access article distributed under the terms and conditions of the Creative Commons Attribution license (http://creativecommons.org/licenses/by/3.0/). 